УДК 595.34:291.2(262.5)

\title{
First Observations of Tumor-Like Anomalies in Planktonic Copepods in the Crimean Coastal Waters
}

\author{
Ekaterina A. Galagovets* and Irina Yu. Prusova \\ A.O. Kovalevsky Institute of Marine Biological Research RAS \\ 2 Nakhimov, Sevastopol, 299011, Russia
}

Received 18.06.2016, received in revised form 24.08.2016, accepted 08.10.2016

In copepods from zooplankton samples collected in coastal waters of the Crimea near Sevastopol in 2011-2012, external tumor-like anomalies (TLA) were found. These anomalies are presumed to be parasitic protists (perhaps dinoflagellates of the family Ellobipsidae) or the hernias induced by injuries. Percentage of specimens with TLA varied, depending on the species, from 0.2 to $20.9 \%$. The highest occurrence of TLA was registered in the most abundant species - Acartia clausi and Paracalanus parvus.

Keywords: copepods, tumor-like anomalies (TLA), parasitic dinoflagellates, Ellobiopsidae, the Black Sea.

DOI: $10.17516 / 1997-1389-2016-9-4-441-451$.

(C) Siberian Federal University. All rights reserved

* Corresponding author E-mail address: didobe@mail.ru 


\title{
Первые обнаружения опухолеподобных аномалий
}

\section{у планктонных копепод}

в прибрежных водах Крыма

\author{
Е.А. Галаговец, И.Ю. Прусова \\ Институт морских биологических исследований \\ имени А.О. Ковалевского РАН \\ Россия, 299011, Севастополь, пр. Нахимова, 2
}

У копепод из зоопланктонных проб, собранных у Черноморского побережья Крыма возле Севастополя в 2011-2012 г2., обнаружены аномальные наружные выросты, которые предположительно являются паразитическими протистами (возможно, динофлагеллятами семейства Ellobiopsidae), а также могут быть выпячиваниями тканей рачков, образовавшимися вследствие травм. Доля особей с аномалиями в общей численности вида варьировала в зависимости от вида от 0,2 до 20,9 \%. Наибольшая встречаемость аномальных выростов установлена у самых массовых видов - Acartia clausi u Paracalanus parvus.

Ключевые слова: копеподы, опухолеподобные аномалии (TLA), паразитические динофлагелляты, Ellobiopsidae, Черное море.

\section{Введение}

Опухолеподобные аномалии (в англоязычной литературе - tumor-like anomalies TLA) отмечаются у различных видов гидробионтов как в морских, так и в пресных водоемах. Данные патологии не связаны со значением слова «опухоль» как «неоплазма» и только по внешнему виду подобны опухолевым образованиям. Так как в русскоязычной литературе нет четкого термина, определяющего это явление, мы остановимся на использовании аббревиатуры TLA, применяемой в иностранных работах. У копепод TLA зарегистрированы в прибрежных водах Италии (Crisafi, Crescenti, 1975), в юговосточной части Тихого океана (Pasternak et al., 1984), в Неаполитанском заливе (Ianora et al., 1990), в Балтийском море (Силина, Худолей, 1994; Щука, 2002), в Великих Озерах (Omair et al., 1999; Bridgeman et al., 2000), в Западном Средиземноморье (Skovgaard, 2004), в Японском море (Konovalova, 2008); у эвфаузиид и декапод - в Северной Атлантике (Mauchline, 1966; Stentiford, Shields, 2005). Большинство исследователей считают, что TLA обусловлены развитием в организмах гидробионтов паразитических форм динофитовых (Dynophyta=Dynoflagellata) водорослей и представляют собой различные стадии жизненного цикла этих простейших (Ianora et al., 1990; Omair et al., 1999; Bridgeman et al., 2000; Manca et al., 2004; Skovgaard, 2004; Konovalova, 2008 и др.).

Сведения о TLA у копепод в Черном море крайне скудны - единственной информацией на эту тему можно считать короткое упоминание о «массовой зараженности копеподы Acartia clausi водорослью Ellobiopsis sp. в Придунайском районе» (Іванов, 1964, с. 53). 
В 2011 г. в ходе выполнения работы по изучению зоопланктонного сообщества бухты Казачьей у значительной части копепод в анализируемых пробах были зафиксированы аномальные наружные выросты, подобные описанным в литературе для других регионов. Впоследствии наличие схожих аномалий зарегистрировали у копепод из открытого прибрежья у Севастополя. Цель настоящей работы - охарактеризовать опухолеподобные аномалии (TLA) и их встречаемость у копепод в прибрежных водах Крыма.

\section{Материалы и методы}

Сбор зоопланктона проводили, как правило, ежемесячно в бухте Казачья в период с января 2011 по декабрь 2012 г. и на станции в 2-мильной зоне от входа в Севастопольскую бухту в марте-октябре 2011 г. В бухте Казачьей на трех станциях в кутовой части (рис. 1А) облавливали вертикально весь слой от дна до поверхности (6-0 и 10-0 м), на станции в устье бухты (рис. 1В) - слой 20-0 м. В открытом прибрежье (2-мильной зоне от входа в Севастопольскую бухту) (рис. 1C) пробы собирали в слое 10-0 м. Отбор проб производили сетью Джеди с площадью входного отверстия $0,1 \mathrm{~m}^{2}$ и размером ячеи фильтрующего сита 132 мкм методом вертикального лова. Пробы фиксировали в 4\%-ном растворе формалина, идентификацию и измерение организмов проводили в камере Богорова под микроскопом МБС-9. Малочисленные формы просчитывали во всей пробе, массовые - в 1/20 или 1/10 части пробы, взятых с помощью штемпель-пипетки объемом 1 и 5 мл в зависимости от количества планктонного содержимого. Взрослых и ювенильных копепод (в том числе и науплиальные стадии) определяли до вида, остальных животных до как можно более низкого таксономического уровня. В ходе стандартной обработки зоопланктонных проб проводили учет особей c TLA. Отмечали местоположение аномалий, фиксировали их размеры. Всего проанализировано 62 пробы.

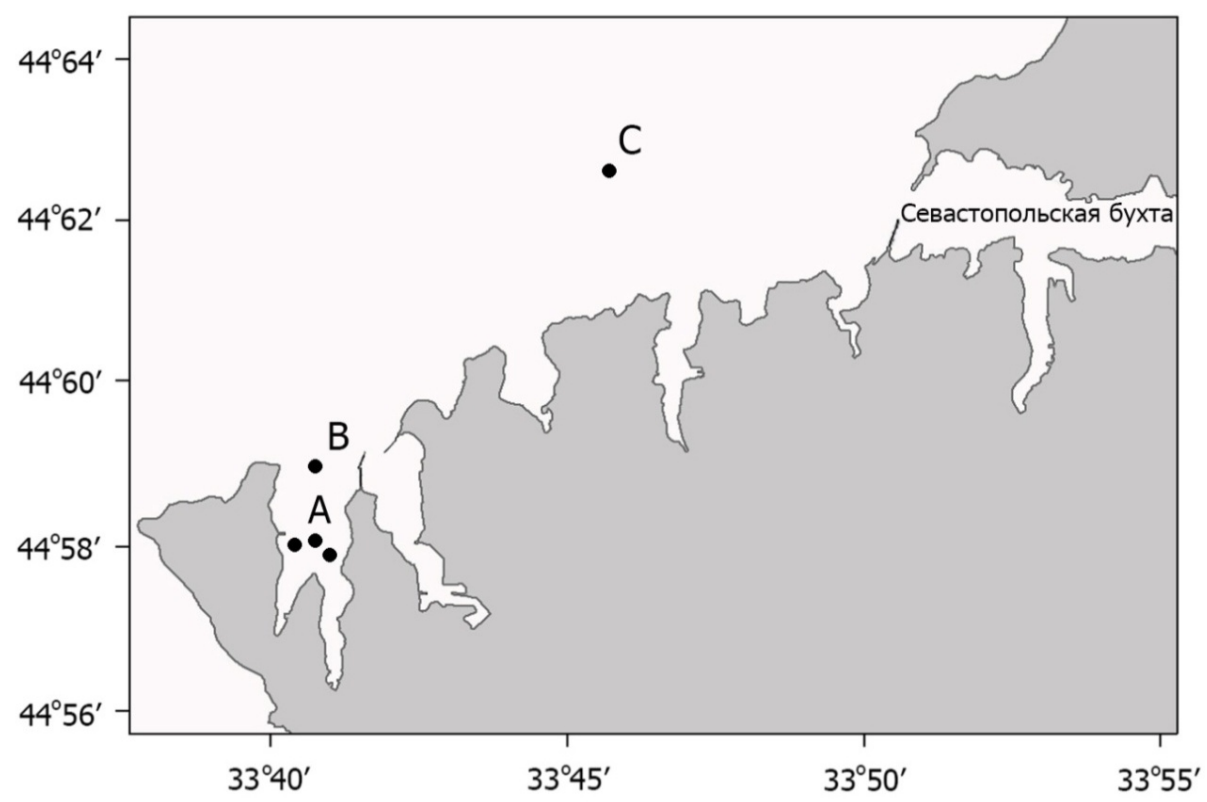

Рис. 1. Местоположение станций сбора проб. А, В - бухта Казачья; С - 2-мильная зона

$$
-443-
$$


С целью убедиться, что аномалии у копепод являются прижизненными, зоопланктон в 6-и пробах из Казачьей бухты, собранных в разные сезоны, исследовали сразу после сбора без фиксации. Перед исследованием «живую» пробу аккуратно сгущали, убирая излишнюю воду при помощи резиновой груши, и затем просматривали в чашке Петри.

Для более детального изучения опухолеподобных аномалий выполнены гистологические исследования. Рачков с TLA, предназначенных для гистологического исследования, переносили из 4\%-ного раствора формалина в фиксатор Буэна. За каждым объектом был закреплен его личный номер, фотография и папка с данными. Использовались как половозрелые, так и ювенильные особи. Образцы были обезвожены, пропитаны парафином, спрессованы, порезаны на срезы толщиной не более 7 мкм и окрашены. Срезы выполняли продольным сечением в дорсовентральном направлении. Окрашивание проводили различными гистологическими методами: окраска железным гематоксилином по Гейденгайну, азур-эозином по Романовскому, полихромное окрашивание по Маллори и по Манну (Роскин, Левинсон, 1957). Всего было изготовлено более 1500 срезов. К сожалению, часть материала, отобранного для приготовления гистологических срезов, была утрачена в процессе работы. Некоторые рачки потеряли свой первоначальный вид в результате дегидратации. Процессы дегидратации и инфильтрации делают рачков практически невидимыми в расплавленном парафине, что в сочетании с их малыми размерами практически лишает возможности задать объекту то положение в блоке, которое лучше всего бы подошло для получения информативных срезов. В результате не все препараты были пригодны для дальнейшего рассмотрения.
Фотографии делали с помощью цифровой камеры DCM130E, закрепленной на микроскопе Leica DM LS2. Измерения копепод и TLA проводили с помощью микроскопа МСП 2. Сравнение средних осуществляли с использованием $t$-критерия для независимых выборок.

\section{Результаты}

В проанализированном материале зарегистрировано 32 таксона зоопланктона, включая копепод (Copepoda), кладоцер (Cladocera), аппендикулярий (Appendicularia), щетинкочелюстных (Chaetognatha), личинок двустворчатых (Bivalvia) и брюхоногих (Gastropoda) моллюсков, полихет (Polychaeta), декапод (Decapoda), форонид (Phoronida), науплиусов усоногих раков (Cirripedia). Среди копепод отмечены 11 видов, принадлежащих к отрядам Calanoida, Cyclopoida, Monstrilloida, a также неопределенные до уровня вида представители отряда Harpacticoida (табл. 1).

Опухолеобразные аномалии (TLA) были найдены в 95 \% проб из обеих исследованных акваторий и только у копепод. Рачки с TLA отмечены во все сезоны. Аномальные новообразования присутствовали у особей обоих полов и всех стадий развития - самок, самцов, копеподитов и науплиусов (рис. 2). TLA чаще всего встречались на дорзальной поверхности копепод, в месте сочленения 1-го и 2-го просомальных члеников, реже - на вентральной стороне, головном отделе и уросоме (в месте сочленения полового сегмента с последним торакальным). По форме и размерам TLA были разнообразны - округлые и удлиненные, с темным содержимым и полупрозрачные с гранулярной структурой, имеющие «стебелек» и прилежащие непосредственно к карапаксу (рис. 2). Длина TLA варьировала от 0,06 до 1,27 мм, но, как правило, не превышала 0,18-0,28 мм, что составляло 5-30 \% от 
Таблица 1. Видовой состав и средняя численность (экз/м³) копепод в бухте Казачьей (01.2011-12.2012; 52 пробы) и открытом прибрежье у Севастополя (04.2011-10.2011; 10 проб)

\begin{tabular}{llcc}
\hline \multirow{2}{*}{ Отряд } & \multicolumn{1}{c}{ Вид } & \multicolumn{2}{c}{ Численность $\pm \sigma^{*}$} \\
\cline { 3 - 4 } & Acartia clausi Giesbrecht, 1889 & Б. Казачья & 2-мильная зона \\
\hline & Acartia tonsa Dana, 1849 & $788,2 \pm 1656,7$ & $1798,9 \pm 799,3$ \\
**Calanus euxinus Hulsemann, 1991 & $4,9 \pm 14,6$ & 0 \\
Calanoida & Centropages ponticus Karavaev, 1894 & $156,4 \pm 228,3$ & $397,9 \pm 907,7$ \\
& Paracalanus parvus (Claus, 1863) & $132,8 \pm 309,3$ & $121,9 \pm 198,9$ \\
& Pontella mediterranea (Claus, 1863) & $723,5 \pm 1001,1$ & $1686,5 \pm 1868,6$ \\
& Pseudocalanus elongatus (Boeck, 1865) & $0,1 \pm 0,5$ & 0 \\
Cусlopoida & Cyclopina gracilis (Claus, 1863) & $175,2 \pm 263,4$ & $326,2 \pm 592,3$ \\
\hline Monstrilloida & Monstrillopsis zernowi Dolgopol'skaya, 1948 & $0,5 \pm 1,6$ & 0 \\
\hline Harpacticoida & & $568,9 \pm 841,5$ & $335,3 \pm 547,4$ \\
\hline Итого \& Orsi, 1984 & Oithona similis Claus, 1866 & $157,9 \pm 414,6$ & $94,6 \pm 162,6$ \\
\hline Copepoda & & $0,1 \pm 0,2$ & 0 \\
\hline
\end{tabular}

* б-величина стандартного отклонения.

** - C. euxinus был представлен, в основном, младшими копеподитами и науплиусами.

общей длины тела рачка. На гистологических срезах TLA имели различные проявления. Одни состояли из вещества без определенной клеточной структуры (рис. $3 B$ ). Другие имели ярко выраженную гранулярную структуру и многочисленные круглые тельца (рис. $3 D$ ). На некоторых срезах опухоль выглядит как продолжение внутренних органов пораженного хозяина (рис. $3 F$ ).

В ходе исследования живого зоопланктона в каждой из шести просмотренных проб были отмечены живые и активно двигающиеся рачки с новообразованиями, сходными по общему виду и размерам с теми, что найдены у копепод в фиксированном материале. Проведенные наблюдения свидетельствуют о том, что аномальные новообразования не являются результатом фиксации проб формалином.

Анализ встречаемости TLA у копепод показал, что доля рачков, имеющих опу- холеподобные аномалии, варьировала в среднем от 0,2 до $20,9 \%$ от общей численности рачков в пробах. Самая высокая доля рачков с аномалиями отмечена у $P$. parvus $(16,0-20,9 \%)$ и A. clausi $(10,1-15,5 \%)$ в бухте Казачьей (рис. 4), в то время как у других видов в этой акватории данный показатель не превышал 7,7-12,0 \%. В открытом прибрежье явного доминирования видов по признаку наличия у них TLA не наблюдалось: доля рачков с аномалиями среди A. clausi, $P$. parvus, O. similis и $P$. elongatus варьировала в пределах 6,4-7,7 \%; у O. davisae, C. ponticus и C. euxinus она составляла 0,$2 ; 2,7$ и $3,4 \%$ соответственно (рис. 4). По усредненным для каждой из двух акваторий данным, в бухте Казачьей встречаемость TLA у копепод в целом была выше, чем в открытом прибрежье, $-10,0$ и 7,4 \% соответственно, но различия статистически недостоверны $(\mathrm{p}>0,1)$. 


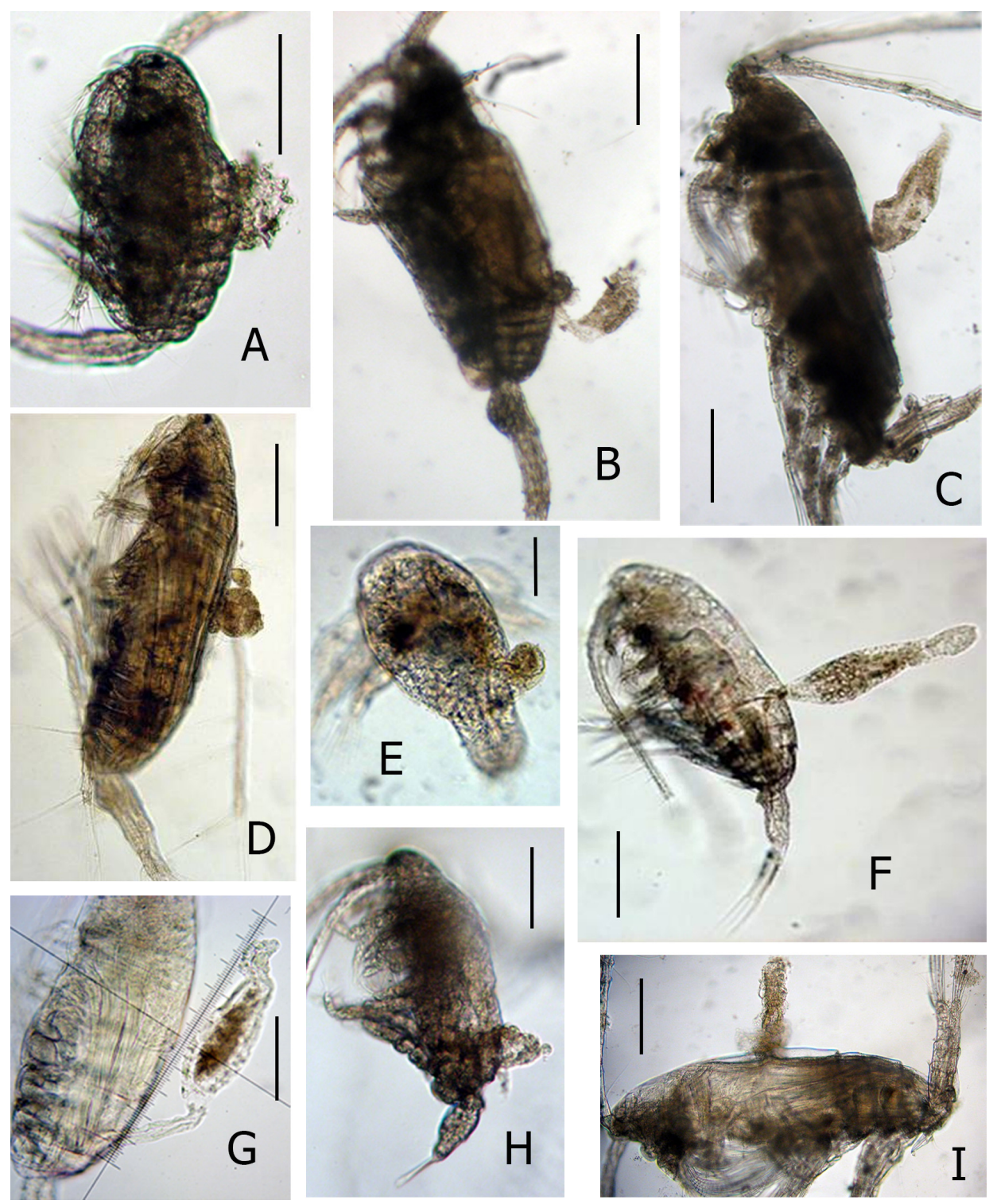

Рис. 2. Копеподы с опухолеобразными аномалиями в исследованном материале. А - Oithona davisae, копеподит пятой стадии; В - Pseudocalanus elongatus, самка; C, D, I - Acartia clausi, самка; E - Calanus euxinus, науплиус; F - Paracalanus parvus, самка; G - Acartia clausi, самец; H - Centropages ponticus, копеподит первой стадии. Масштабные отрезки: А, E, Н - 0,1 мм; B, C, D, F, G, I - 0,2 мм

\section{Обсуждение}

Сравнение наших образцов, исследованных методами световой микроскопии и гистологического анализа, с фотографиями и описаниями, имеющимися в литературных источниках, дает основание предполагать, что, по крайней мере, часть TLA - это проявления жизнедеятельности паразитических организмов, в частности динофлагеллят семейства Ellobiopsidae, описанных Н. Boschma (1956) и Г.В. Коноваловой (Konovalova, 2008). Ellobiopsidae часто отмечаются как паразиты веслоногих ракообразных (Théodoridès, 1989; Shields, 1994; Bridgeman et al., 2000; Albaina, Irigoien, 2006; Konovalova, 2008). Это семейство представляет собой небольшую 

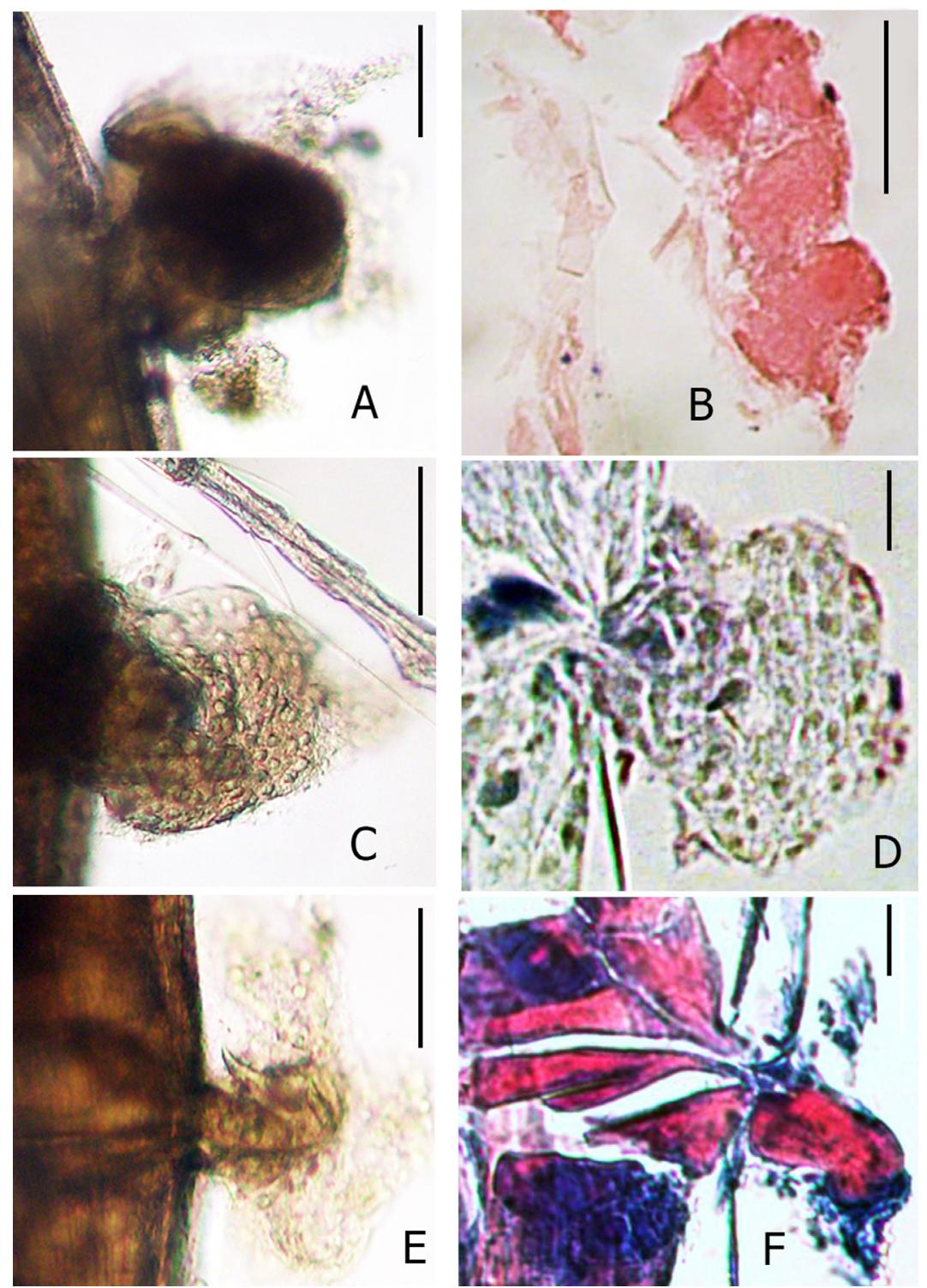

Рис. 3. Внешний вид (слева) и гистологические срезы (справа) аномальных образований у копепод из исследованного материала. A-B, C-D, E-F - TLA на дорсальной поверхности карапакса между 1-м и 2-м члениками просомы у трех разных особей Acartia clausi; В - окрашивание по методу Манна; $\mathrm{D}$ - окрашивание по методу Романовского ; F - окрашивание по методу Маллори. Масштабные отрезки: A, B, C, E-0,05 мм; D, F-0,02 мм

гетерогенную группу паразитических протистов, имеющую несомненное родство с динофлагеллятами, однако четко систематическое положение эллобиопсид не определено (Bridgeman et al., 2000; Konovalova, 2008). Для эллобиопсид характерно наличие закрепленного внутри и проходящего через кути- кулу тела рачка-хозяина одного трофомера и одного или нескольких выходящих из него гономеров. Трофомер служит для прикрепления паразита к телу хозяина и высасывания из него питательных соков. Незрелые стадии паразита, как правило, имеют грушевидную форму. По мере роста паразита его форма 


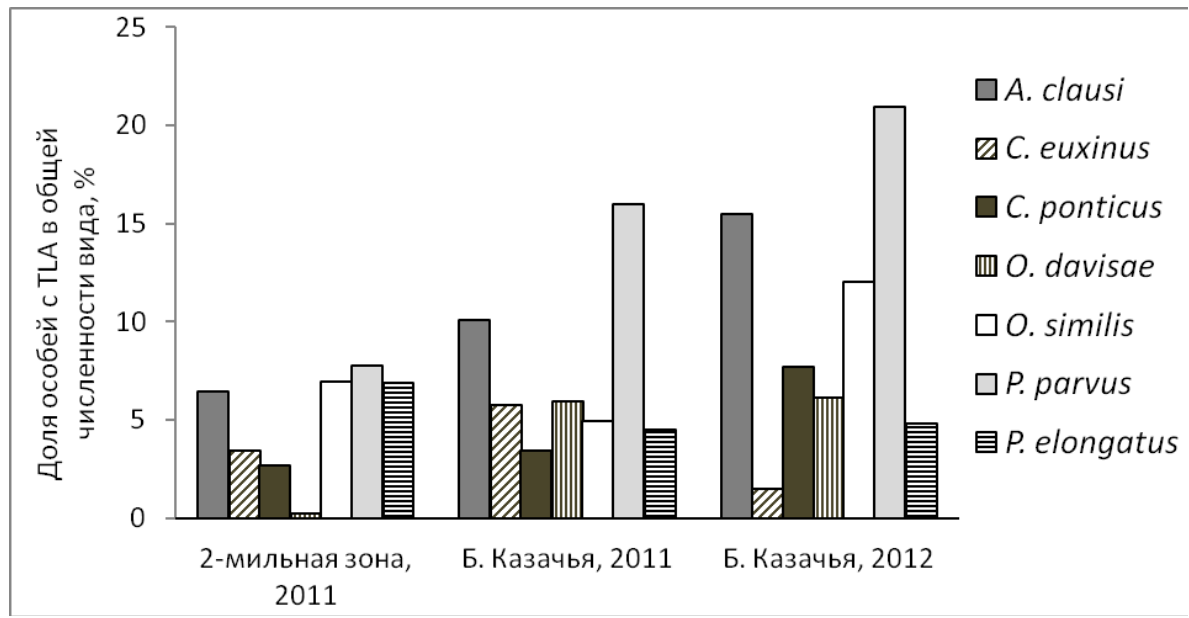

Рис. 4. Доля копепод с опухолеподобными аномалиями в общей численности каждого из наиболее массовых видов в бухте Казачьей и открытом прибрежье у Севастополя в 2011 и 2012 гг.

вытягивается и из трофомера при помощи перетяжки на дистальном конце паразита образуется один или несколько гономеров. Гономер - плодоносящая стадия паразита, имеет цилиндрическую (Konovalova, 2008) или шаровидную (Skovgaard, Saiz, 2006) форму и в разной степени гранулированное содержимое (рис. $5 E$ ). По мере созревания гономера от него отделяются округлые многоядерные клетки, которые затем распадаются на более мелкие одноядерные споры (Киселев, 1950; Konovalova, 2008).

При всем большом разнообразии форм и размеров TLA, отмеченных в исследованном материале, их можно разделить на три основные группы: 1) удлиненные, веретеновидные или грушевидные, часто имеющие зернистую структуру (рис. $2 B, C, F, G, I$; рис. $5 A-$ $D)$; 2) округлые, плотные по структуре, как правило, небольшие по величине (рис. $2 D, E$ ); 3) бесформенные, с неопределенной структурой (рис. $2 A, H$ ). У TLA первой группы можно различить структуры, подобные указанным для зрелых трофомеров эллобиопсид. Во многих случаях заметны тяжи, соединяющие TLA и ткани рачка (рис. $5 A-B$, показаны стрелками), что дополнительно указывает на паразитический характер новообразования. TLA этой группы составляли в среднем от 4,2 до $40,9 \%$ от общего количества аномалий у разных видов копепод в бухте Казачьей и от 0,0 до 52,5 \% - в открытом прибрежье. TLA, условно объединенные во вторую группу, вероятно, также можно отнести к паразитическим динофлагеллятам, но более ранних стадий развития трофонтов. TLA третьей группы могут быть обусловлены выпячиваниями тканей рачка (рис. $3 E, F)$. Возможно, такие грыжеподобные образования спровоцированы ранами, вызванными хищниками. Есть мнение, что выпячивание собственных тканей рачка может быть следствием неудачной попытки эллобиопсид закрепиться на рачке, когда паразит проделывает отверстие в карапаксе, но отпадает (Bridgeman et al., 2000; Omair et al., 2001). Так как TLA чаще всего встречались в месте сочленения сегментов, можно предположить, что эти области наиболее уязвимы к воздействию извне, особенно в период линьки. В результате механического воздействия на карапакс, а именно на интерсегментальные сухожилия, происходит раз- 


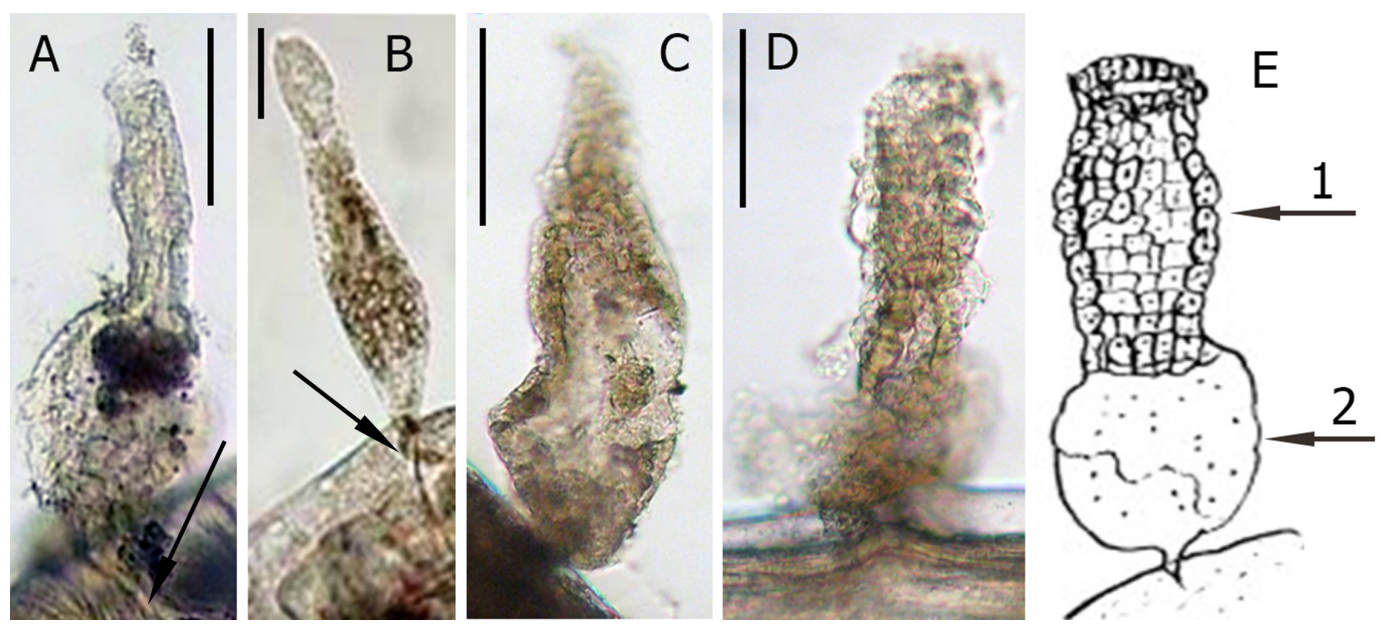

Рис. 5. Сравнение опухолеподобных аномалий копепод в исследованном материале (A-D, стрелками показаны тяжи, соединяющие TLA с тканями рачка) с рисунком Ellobiopsis sp. в стадии спороношения (E, 1 - трофомер; 2 - гономер; по: Konovalova, 2008). Масштабные отрезки: A, B, C, D - 0,1 мм

рыв гиподермального эпителия, в результате чего мышечная ткань выпячивается наружу. В случае более глубокого повреждения через рану может, вероятно, выйти и содержимое гонад. Таким образом, наличие опухолеподобных аномалий у копепод свидетельствует об их травмированности или о зараженности паразитическими протистами.

TLA зарегистрированы у всех видов копепод во все сезоны в обеих исследованных акваториях, что свидетельствует о значительном масштабе этого явления в прибрежных водах Крыма. Наибольшая встречаемость данных аномалий установлена у самых массовых видов - Acartia clausi и Paracalanus parvus, при этом в бухте Казачьей она была недостоверно выше, чем в открытом прибрежье. TLA удлиненной формы с зернистой структурой, которые с большой долей вероятности можно считать эктопаразитами, составляли в некоторых случаях до 52,5 \% от общего количества аномалий.

\section{Заключение}

Паразитарные инфекции копепод, несомненно, влияют на функциональные ха- рактеристики как отдельных особей, так и популяций в целом. Травмированность, а следовательно, и физиологическая ослабленность части рачков сказываются на состоянии популяций. В связи с этим опухолеподобные аномалии копепод как свидетельства наличия травм или зараженности рачков паразитами могут служить одним из показателей состояния популяций этих ракообразных. Поиск связей между распространенностью TLA среди копепод и структурно-функциональными характеристиками популяций этих ракообразных является важной научной задачей и заслуживает тщательного изучения.

\section{Благодарности}

Авторы выражают глубокую благодарность В.К. Мачкевскому за помощь в подготовке и проведении гистологического анализа, О.И. Беляевой за организацию отбора проб зоопланктона в бухте Казачьей и всестороннюю помощь в процессе сбора материала, С.А. Хворову, Д.А. Алтухову и А. Матвееву за помощь в отборе проб зоопланктона, Г.В. Коноваловой, А.В. Макрушину, И.В. Довгалю 
за ценные консультации по определению природы опухолеподобных аномалий копепод в исследованном материале, рецензентам - за ценные замечания.

\section{Список литературы}

Іванов О.І. (1964) До характеристики систематичного складу фітопланктону північнозахідноі частини Чорного моря. Наукові записки Одеської біологічної станції. Вип. 5. Топачевський О.В. (ред.), с. 51-54 [Ivanov A.I. (1964) То the characteristics of systematic composition of phytoplankton North-western part of the Black Sea. Scientific Notes of the Odessa Biological Station. Issue 5. Topachevsky O.V. (ed.), p. 51-54 (in Ukrainian)]

Киселев И.А. (1950) Панцирные жгутиконосиьы (Dinoflagellata) морей и пресных вод СССР. М; Л, АН СССР, 279 c. [Kiselev I.A. (1950) Dinophyceae (Dinoflagellate) seas and fresh waters of the USSR. Moscow; Leningrad, AS USSR, 279 p. (in Russian)]

Роскин Г.И., Левинсон Л.Б. (1957) Микроскопическая техника. М., Советская наука, 476 с. [Roskin G.I., Levinson L.B. (1957) The microscopic technique. Moscow, Sovetskaya nauka, 476 p. (in Russian)]

Силина Н.И., Худолей В.В. (1994) Опухолеподобные аномалии у планктонных веслоногих. Гидробиологический журнал, 23(3): 96-99 [Silina N.I., Khudolei V.V. (1994) Tumorlike anomalies in planktonic copepods. Hydrobiological Journal [Gidrobiologicheskij zhurnal], 30: 5255 (in Russian)]

Щука Т.А. (2002) Характеристика современного состояния зоопланктона Балтийского моря: автореф. дис. ... канд. биол. наук: 03.00.16. Москва, 28 с. [Shyuka T.A. (2002) Characteristics of the current state of the Baltic Sea zooplankton. Abstract of PhD thesis in Biology: 03.00.16. Moscow, 28 p. (in Russian)]

Albaina A., Irigoien X. (2006) Fecundity limitation of Calanus helgolandicus, by the parasite Ellobiopsis sp. Journal of Plankton Research, 28 (4): 413-418

Boschma H. (1956) Ellobiopsidae. Conseil International pour l'Exploration de la Mer Zooplankton Sheet, 65: 1-4

Bridgeman T.V., Messick G., Vanderploeg H.A. (2000) Sudden appearance of cysts and ellobiopsid parasites on zooplankton in a Michigan lake: a potential explanation of tumor-like anomalies. Canadian Journal of Fisheries and Aquatic Sciences, 57 (8): 1539-1544

Crisafi P., Crescenti M. (1975) Conseguenze delle attivita umane sullo zooplancton del Mare di Taranto. Boll Pesca Piscic. Gidrobiol., 30: 207-218

Ianora A., Scotto di Carlo B., Mazzocchi M.G. (1990) Histomorphological changes in the reproductive condition of parasitized marine planktonic copepods. Journal of Plankton Research, 12 (2): $249-258$

Konovalova G.V. (2008) Parasitic dinoflagellates and ellobiopsids (Ellobiopsidae) of the coastal waters of the sea of Japan. Russian Journal of Marine Biology, 34 (1): 28-37

Manca M., Carnovale A., Alemani P. (2004) Exotopic protrusions and ellobiopsid infection in zooplanktonic copepods of a large, deep subalpine lake, Lago Maggiore, in northern Italy. Journal of Plankton Research, 26 (11): 1257-1263

Mauchline J. (1966) Thalassomyces fagei, an ellobiopsid parasite of the euphasiid crustacean, Thysanoessa raschi. Journal of the Marine Biological Association of the United Kingdom, 46 (3): 531-539 
Omair M., Vanderploeg H.A., Jude D.J., Fahnenstiel G.L. (1999) First observations of tumor-like abnormalities (exophytic lesions) on Lake Michigan zooplankton. Canadian Journal of Fisheries and Aquatic Sciences, 56 (10): 1711-1715

Omair M., Naylor B., Jude D.J., Quddus J., Beals T.F., Vanderploeg H.A. (2001) Histology of herniations through the body wall and cuticle of zooplankton from the Laurentian Great Lakes. Journal of Invertebrate Pathology, 77 (2): 108-113

Pasternak A.F., Arashkevich Ye.G., Sorokin Yu.S. (1984) The role of the parasitic algal genus Blastodinium in the ecology of planktonic copepods. Oceanology, 24: 748-751

Shields J.D. (1994) The parasitic dinoflagellates of marine crustaceans. Annual Review of Fish Diseases, 4: 241-271

Skovgaard A. (2004) Tumor-like anomalies on copepods may be wounds from parasites. Journal of Plankton Research, 26 (9): 1129-1131

Skovgaard A., Saiz E. (2006) Seasonal occurrence and role of protistan parasites in coastal marine zooplankton. Marine Ecology Progress Series, 327: 37-49

Stentiford G.D., Shields J.D. (2005) A review of the parasitic dinoflagellates Hematodinium species and Hematodinium-like infections in marine crustaceans. Diseases of Aquatic Organisms, 66: 47-70

Theodorides J. (1989) Parasitology of marine zooplankton. Advances in Marine Biology, 25: 117177 